\title{
IDEOLOGY AND VOTE CHOICE IN THE 2004 ELECTION
}

\author{
William G. Jacoby \\ Michigan State University \\ May 2008 \\ jacoby@msu.edu
}

Prepared for delivery at the Shambaugh Conference on "The

American Voter: Change or Continuity Over the Last Fifty Years."

Department of Political Science, the University of Iowa, May 8-10, 2008. 


\begin{abstract}
This paper examines the impact of liberal-conservative ideology on voting behavior in the 2004 presidential election. The analysis uses data from the CPS National Election Study for that year. The empirical results show that liberal-conservative identifications exerted no direct impact on voting choices within the 2004 electorate. However, there was widespread recognition of the candidates' and parties' ideological positions. And, liberal-conservative identifications did show an indirect effect which operated through their influence on the more proximate determinants of electoral decisions. These findings clarify the role of ideology in the 2004 presidential election; they also conform very closely to the basic theoretical structure laid out in The American Voter.
\end{abstract}


This paper examines the role of ideology as a determinant of recent voting behavior in the American electorate. The analysis uses data from the 2004 CPS National Election Study, and the empirical results suggest a somewhat complicated interpretation. On the one hand, liberal-conservative orientations had no direct impact whatsoever on citizens' voting choices. On the other hand, mass perceptions and evaluations of the candidates, issues, and conditions within the external environment were clearly structured along ideological lines. And, the latter did influence electoral decisions. Therefore, liberal-conservative ideology exerted an important, but completely indirect, effect on citizens' 2004 voting choices. These findings have important implications, not only for understanding the role of ideology in American elections, but also for theories of voting behavior.

\section{BACKGROUND}

Over the years, scholars of mass political behavior have treated ideology in two different ways. One perspective, drawn from The American Voter and Philip Converse's (1964; $1970 ; 1975)$ seminal studies of citizens' belief systems, stresses the weak effects of liberalconservative orientations, due to cognitive limitations within the electorate and the resultant general inability (or unwillingness) to deal with ideological abstractions (Kinder 1983). The alternative perspective emphasizes that many people make electoral decisions which are consistent with their own liberal-conservative identifications, even if they use these labels in a non-ideological manner (e.g., Levitin and Miller 1979)

Efforts to reconcile these two potentially contradictory views of ideology have also proceeded along two somewhat different paths. First, a number of scholars have shown that there are pronounced individual differences within the electorate in terms of the propensity to view the world through a liberal-conservative lens. Stated simply, some people organize their attitudes and behavior along ideological lines while others do not (e.g., Jacoby $1986 ; 1988 ; 1991)$. The former comprise a fairly small subset of the overall public, generally well-educated and relatively involved with the political world. Second, researchers have also

emphasized that liberal-conservative labels have affective value in themselves even if they 
are not reflections of a coherent, underlying ideology (e.g., Conover and Feldman 1981). In this latter capacity, personal attachments to "liberal" or "conservative" still enable people to sort the political world into "us" and "them," and thereby serve as a useful heuristic device for making electoral decisions (Sears, Lau, Tyler, Allen 1980; Sears 1993).

Combining the preceding two lines of research, the current consensus seems to be that ideological themes are relatively pervasive within American public opinion. But, the affective content of liberal-conservative terms predominates at lower levels of political sophistication, while their utility as cognitive structuring mechanisms comes to the forefront among more knowledgeable people (Sniderman, Brody, Tetlock 1991). In any event, political scientists have generally regarded ideology as a major influence on voting behavior in recent presidential elections even though the psychological mechanisms underlying its impact may vary across strata within the mass public (e.g., Knight 1985; Alvarez and Nagler 1995; 1998; Miller and Shanks 1996).

The campaign rhetoric manifested during the 2004 election period did not particularly focus on ideological themes. But, four years of Bush administration's aggressively conservative policy initiatives, combined with the Kerry organization's overt attempt to mobilize traditionally liberal constituencies, made it very easy for people to sort out the relative ideological positions associated with the two presidential candidates. And, it seems reasonable to expect that this clarity would be reflected in the ways that citizens reached their voting decisions.

\section{DATA}

Note that the objective of this analysis is not to construct a detailed representation of the precise causal structure underlying individual vote choice. Instead, it is to summarize in a parsimonious manner the effects of several variables which have been featured prominently in substantive theories of mass political behavior or which reflect salient elements of the 2004 campaign environment. Of course, we will pay particular attention to the impact of citizens' 
liberal-conservative orientations, relative to the other hypothesized influences on electoral decisions.

Fortunately, the 2004 CPS National Election Study provides exactly the kind of information required to examine the impact of ideology on voting behavior in that year's presidential election. The dependent variable for the analysis is each individual's choice between George W. Bush and John Kerry. Although Ralph Nader received quite a bit of publicity as a third-party candidate, he attracted very little electoral support. There is only a tiny handful of Nader voters among the 2004 NES respondents and they are simply omitted from this portion of the analysis. ${ }^{1}$ Therefore, the dependent variable is a dichotomy, with Bush voters coded one and Kerry voters coded zero.

The independent variables are divided into three subsets composed of two variables each. First, and most relevant to the present study, there are long-term symbolic predispositions. Party identification and Liberal-conservative self-placement both develop early in life, as the first real consequences of the general political socialization process. From there, they serve as relatively stable "platforms" for evaluating more transitory political stimuli. Party identification is almost universally regarded as a group attachment. As explained earlier, ideological self-placements could work in several different ways. But, regardless of the exact process, it will be the major focus of attention below. Both of these variables are measured using the standard seven-point scales that have been included in the NES interview schedules for many years; they are coded so that larger values indicate stronger Republican/more extreme conservative identifications.

The second subset of variables is composed of two relatively proximal political influences on voting choice: Comparative evaluations of the candidates' personality traits and summaries of individual issue stands. Both of these variables are operationalized as multiple- item scales. The personality assessment measure is obtained from the NES respondents' beliefs about the degrees to which Bush and Kerry possessed seven personality traits. ${ }^{2}$ Specifically, the response scores are recoded so that larger values indicate more positive evaluations. Each 
respondent's mean score (i.e., across the seven traits) for Kerry is subtracted from his/her mean score for Bush. The resultant scale is highly reliable (Cronbach's alpha is 0.906) and it summarizes the degree to which people believe that Bush possesses more desirable personality characteristics than Kerry. The measure of issue attitudes is obtained by taking each respondent's mean score across the seven-point issue scales included in the pre-election wave of the 2004 NES. ${ }^{3}$ Again, the scale is very reliable, with an Alpha coefficient of 0.740 . It is coded so that higher scores indicate more conservative issue stands.

The third subset of variables taps individual retrospective evaluations. One variable measures assessments of the Iraq war, using a summated rating scale constructed from two items (Cronbach's Alpha equals 0.647). ${ }^{4}$ The other variable summarizes sociotropic economic judgments, by combining responses to questions about whether the national economy, inflation, and unemployment had gotten better or worse over the preceding year (Alpha equals 0.752 ). Both of these scales are coded so that larger values indicate more optimistic judgments about conditions in the respective contexts.

\section{IDEOLOGY AND VOTE CHOICE IN 2004}

Let us begin with a relatively simple model which tests the direct effects on vote choice in 2004. Table 1 shows the maximum likelihood coefficients, standard errors, and odds ratios obtained when the six independent variables are used to predict voting for George $\mathrm{W}$. Bush in a logistic regression model. The equation fits the data very well, with a pseudo$\mathrm{R}^{2}$ value of 0.778 . As one might expect from such a good fit, most of the independent variables have coefficients that are statistically different from zero, in the expected directions. Personality assessments have the strongest impact, by far: A single unit increase in preference for Bush's traits over Kerry's traits corresponds to a nearly eightfold increase in the odds of a Bush vote. Issue attitudes have the second-strongest effect, with a single unit movement in the conservative direction doubling the odds of a Bush vote. Sociotropic judgments, party identification, and feelings about the Iraq war all have smaller, but still significant, effects. A single-unit, pro-incumbent difference on any of these variables (i.e., more positive about 
the economy and/or the war, more Republican identification) increases the odds of a Bush vote by a magnitude that ranges from about $43 \%$ (for feelings about Iraq) to about $78 \%$ (for retrospective economic judgments).

For present purposes, the most important result involves the one independent variable in Table 1 with a nonsignificant impact: Liberal-conservative identification. The maximum likelihood coefficient estimate for this variable is positive (as expected), but it is quite small (0.247) relative to both its standard error (0.188) and the coefficients for the two other seven-point scales included in the equation (i.e., 0.756 for the issue attitude variable and 0.510 for party identification). A one-unit movement in the conservative direction along the ideological continuum only corresponds to a $28 \%$ increase in the odds of a Bush vote. Thus, it appears that liberal-conservative self-placements do not exert a direct influence on individuals' 2004 voting choices.

The null result for ideology is intriguing not only because of the general prominence of this variable in theories of mass behavior, but also because the conceptually similar variables measuring party identification and personal issue stands both exert clearcut and fairly strong effects on electoral decisions. So, an obvious question arises: Why is ideology different?

One possible answer to that question might be that individual differences are "masking" the impact of ideology. This could occur if a large stratum of nonideological voters coexists with a relatively small ideologically oriented subset within the electorate. In that case, the net effect of liberal-conservative placements might appear to be negligible, even though they are highly important for certain people.

This latter possibility can be tested by estimating a conditional effects model which allows the impact of the six explanatory variables to differ across levels of political sophistication. In the NES data, sophistication can be measured by counting up the number of correct answers that each respondent gives to six factual questions about American politics. ${ }^{5}$ This political knowledge index is used to create six multiplicative terms by taking its product with each of the other independent variables. 
Table 2 presents the maximum likelihood estimates for a logistic regression model that includes the original explanatory variables, the knowledge index, and the multiplicative terms between them. The leftmost column shows the coefficients for the six variables- these are their effects at the lowest sophistication level (i.e., when the knowledge index is equal to zero). The right-hand column gives the coefficients for the respective multiplicative terms. These give the difference in the impact of each explanatory variable that coincides with movement from the minimum to the maximum value on the knowledge variable.

The results in Table 2 show that the influences on voting choice do not change across levels of political sophistication. All six multiplicative terms have small, nonsignificant coefficients. Overall, allowing for variation across political sophistication strata within the electorate does not improve predictions of voting choice: Comparing the conditional-effects model in Table 2 to the original equation from Table 1 produces a likelihood ratio chi-square statistic of 5.95. With seven degrees of freedom, the observed probability value for this test is 0.545 ; thus, the null hypothesis of no difference between the two models cannot be rejected.

Clearly, the lack of liberal-conservative influence on voting choice is uniform throughout the 2004 electorate. It simply is not the case that a small subset of ideologically-attuned people are being "masked" by a larger nonideological group of citizens. So, again, it remains important to determine why this occurs.

\section{IDEOLOGY IN THE 2004 CAMPAIGN ENVIRONMENT}

Elections involve an interactive relationship between political elites and the mass public. Citizen behavior reflects the kinds of stimuli that are prominent within the external campaign environment. This general observation is relevant to the present context because, as mentioned earlier, ideological rhetoric was not especially prominent in 2004. Therefore, people may have not been thinking about the candidates and parties in liberal-conservative terms. And, if that were the case, there would definitely be no reason to expect ideologically motivated voting choices. 
Table 3 presents some data that are relevant to this point. The leftmost column of the table shows the percentage of the NES respondents who were willing to place each of the candidates and the two major parties along the liberal-conservative continuum. Obviously, most people had little difficulty doing so: For Bush, Kerry, and the two major parties, the figures hover consistently around 90\%. Even for the relatively unfamiliar figure of Ralph Nader, almost two- thirds of the respondents were able to come up with a position along the ideological dimension.

Of course, willingness to place the candidates/parties is only the first step. Because of the potential for rationalization of personal issue positions and/or simple acquiescence among the survey respondents, it is not unreasonable to question the substantive validity of the ideological placements. Therefore, the second and third columns of Table 3 report the percentages of the NES respondents who placed each candidate or party within the "correct" and "incorrect" regions of the seven-point liberal-conservative scale, respectively. ${ }^{6}$ For the more familiar political figures, the percentages, again, suggest fairly widespread willingness to use these abstractions in order to describe the candidates and parties. Slightly less than two-thirds of the NES respondents placed Bush, Kerry, the Democratic party, and/or the Republican party at appropriate positions along the ideological dimension, while 10-15\% located them at positions that would generally be considered incorrect. Again, the figures are much lower for Nader: About 40\% placed him on the liberal side, while just under $10 \%$ considered him to be a conservative.

Overall, people appear to be quite adept at using an ideological dimension to describe the relative stands of the major parties and their candidates in 2004. Sizable majorities placed Democratic stimuli on the liberal side, and Republican figures on the conservative side of the bipolar continuum. The results are less clearcut for Ralph Nader. But, that is entirely reasonable, given the lack of publicity and generally idiosyncratic nature of his candidacy.

The results so far show that people can identify ideological positions for the parties and candidates when they are specifically asked to do so. However, such questions might be 
invoking a judgmental standard that people can recognize, but do not actually use on their own. In order to guard against this possibility, it is important to determine how the 2004 electorate thought about the candidates without or "priming" or encouraging the use of specific evaluative dimensions. In other words, what kind of "mental maps" or cognitive structures do people bring to bear on the political world and- more to the point- are they organized along liberal-conservative lines?

Multidimensional scaling (MDS) is an analytic strategy that is ideally suited for dealing with these questions. Speaking generally, MDS represents dissimilarities among a set of stimuli as distances between points in a space. Similar stimuli are represented by points that are located close together; dissimilar stimuli are shown as points that are more widely separated. The objective of the MDS is to obtain a low-dimensioned configuration of points that accurately reflects all pairwise dissimilarities between the stimulus objects (once again, in the sense that greater dissimilarity corresponds to greater distance). The advantages of MDS in the present context are that it (1) provides an empirical estimate of the cognitive map that the electorate brings to bear on the candidates; and (2) it does so without any advance specification of, or restriction on, the evaluative criteria that people employ. Therefore, if ideology does serve to structure public perceptions, it should be apparent in the arrangement of points that is recovered from the MDS.

The input data for the MDS are contained in a matrix of perceptual dissimilarities, created from the feeling thermometer battery in the pre-election wave of the 2004 NES, using the line-of-sight (LOS) methodology developed by Rabinowitz (1976). Basically, this approach assumes that people use the thermometer ratings to respond to the candidates in a manner that is consistent with a spatial model; that is, a high thermometer score indicates that the person is relatively "close" to that candidate, and vice versa for low scores. The LOS procedure uses the geometric implications derived from this assumption to develop a rank-ordered set of dissimilarities between all pairs of the candidates, using the full set of 
thermometer ratings (i.e., across all NES respondents and all candidates included in the battery).

The MDS of the LOS dissimilarities reveals that two dimensions are sufficient to provide a very accurate model of the public's general beliefs about the candidates and parties. Figure 1 shows the "map" of perceived candidate and party points. ${ }^{7}$ This point configuration fits the data perfectly, in the sense that the rank correlation between the input dissimilarities and the scaled interpoint distances is 1.00 . Thus, citizens' perceptions of major figures in the 2004 political world conform to a fairly simple underlying structure.

For substantive meaning of the scaling results is determined by any systematic patterns that exist within the point configuration. Here, the most significant feature is that the horizontal direction within the space does correspond to a general ideological dimension. Points representing more liberal stimuli (e.g., Kerry, Edwards, Bill and Hillary Clinton, the Democratic party, and Ralph Nader) are located near the left side, while conservative stimuli (Ashcroft, Cheney, George Bush, and the Republican party) correspond to points near the right side of the space. The points near the center (of the horizontal direction) represent figures that appeal to either a nonpartisan or bipartisan constituency (i.e., Laura Bush, John McCain, and Colin Powell).

In order to verify this ideological interpretation of citizens' perceptions, the best strategy is to see whether an external measure of each figure's liberal-conservative position can be embedded within the space. Unfortunately, the NES did not have respondents place most of these figures along an ideological scale. Therefore, an indirect indicator must be used: The difference between the mean feeling thermometer rating provided by liberals minus the mean feeling thermometer rating provided by conservatives. This mean value is calculated for each of the candidates and parties included in the MDS configuration. The differences in the mean values should summarize ideologically based variability in citizens' reactions toward those stimuli. 
The multiple correlation between the MDS point coordinates and the candidate-party ideology measure is extremely large, at 0.958. So, this systematic analysis confirms the visual evidence: Citizens' perceptions of the 2004 candidates and parties were fully consistent with liberal-conservative distinctions. ${ }^{8}$ This result is particularly telling, because the NES respondents were not explicitly instructed to use ideological criteria in their evaluations. Instead, they apparently do so without any outside prompting.

In summary, the empirical results presented in this section provide a negative answer to the question motivating this part of the analysis: The lack of direct ideological influence on 2004 voting choices is not due to any lack of ideological content in the political environment or to any public inability to recognize this content. Most people locate the candidates and parties accurately along the liberal-conservative continuum when they are asked to do so. And, their overall perceptions of these figures also appear to be structured along ideological lines. Thus, the external political environment in 2004 certainly could have sustained ideological voting; it is necessary to look elsewhere to determine why it did not occur within the electorate.

\section{PERSONAL IDEOLOGY AND OTHER POLITICAL ORIENTATIONS}

Individual predispositions like party identification and liberal-conservative ideology are particularly important because they develop early and remain very stable throughout a person's life (Sears 1983; Krosnick 1991; Sears and Funk 1999). In this capacity, they shape other political orientations that develop in response to more transitory and/or temporary stimuli like policy issues, the candidates in any specific election, and retrospective judgments about socioeconomic conditions. And, in so doing, partisanship and ideology could exert an indirect effect on voting choices; this would, of course, qualify the negative results reported earlier about the relationship between ideology and the vote. Alternatively, if people do not make the connection between their own liberal-conservative positions and their feelings about candidates, issues, and external conditions, then the null effects of ideology on voting choice are perfectly reasonable. In either case, it is important to examine the impact of 
long-term predispositions- especially ideology- on the other factors that feed into individual electoral decisions.

The empirical tests for indirect effects are provided in Table 4. Specifically, the table shows OLS estimates from four regression equations which measure the impact of party identification and liberal-conservative self-placement on each of the four other predictor variables from the voting model tested back in Table 1: The summary scale of issue attitudes; relative assessments of the presidential candidates' personality traits, judgments about the national economy, and reactions to the Iraq war.

Let us begin by considering the two retrospective assessments. The equation for sociotropic judgments shows a relatively weak fit to the data, with an $\mathrm{R}^{2}$ value of 0.265 . Of the two independent variables, only party identification shows a significant influence. Apparently, partisan affiliations shape individual views about the quality of economic life, but liberal-conservative orientations do not serve in a similar capacity. The model fit is better for Iraq war judgments: The $\mathrm{R}^{2}$ for this equation is 0.414 . And, the coefficients for the two independent variables are statistically significant. Both partisanship and ideology affect individual reactions to the war in Iraq, although the magnitude of the former's impact is about double that of the latter.

Next, consider the two more proximate political influences on voting, issue attitudes and judgments about candidate personality traits. Here, both equations fit quite well, with $\mathrm{R}^{2}$ values of 0.584 and 0.428 , respectively. And, the coefficients for party identification and ideological self-placement are both statistically different from zero (in the expected direction) in each case. Partisanship has a much stronger effect than ideology on personality assessments. This is probably to be expected, since the candidates are representatives of their respective parties and they largely downplayed ideological stands during the campaign. On the other hand, the impact of liberal-conservative orientation on issue attitudes is just as strong as (in fact, slightly stronger than) that of party identification. Ideology does join partisanship in leading people to adopt particular policy stands. 
It is important to emphasize that the overall magnitude of ideology's indirect effect is quite pronounced. A single unit increase on the liberal-conservative variable operates through the various intervening factors to produce a total indirect effect of $0.614 .{ }^{9}$ Stated differently, it increases the odds of a vote for George W. Bush by $84.8 \%$. To place these figures into perspective, the indirect impact of ideology on voting choice is comparable to (and, in fact, slightly larger) than the point estimate for the direct effect of party identification (i.e., the coefficient of 0.510 back in Table 1). ${ }^{10}$ Thus, there was a definite ideological component in the behavior of the 2004 electorate.

The results presented in this section show that people employ ideological considerations in their political reasoning. Hence, the null findings reported earlier clearly are not due to any inability on the part of the electorate to relate liberal-conservative abstractions to their own political preferences. Instead, it is simply that ideology had an indirect, rather than direct, effect on voting choices in 2004.

\section{CONCLUSIONS}

This analysis shows that ideology played a critical role in the 2004 presidential election. The mass public perceived the stimuli associated with the election- candidates, parties, and issues- in explicitly ideological terms. And, individuals' evaluations of those stimuli were shaped by their personal liberal-conservative orientations. At the same time, however, there is an important caveat that qualifies the preceding interpretation: Once feelings about salient electoral objects are taken into account, ideology had no discernible additional impact of its own on voting choices.

Such seemingly ambiguous findings with respect to ideology might be construed as a bit disappointing and anticlimactic. Certainly, they provide a sharp contrast to presidential elections from the 1970s through the 1990s, in which ideological identifications did exert separate and direct influences on voting, at least within some segments of the American public (e.g., Miller, Miller, Raine, Brown 1976; Miller and Levitin 1976; Knight 1985; Alvarez and Nagler 1995; 1998; Miller and Shanks 1996). At the same time, however, the findings 
obtained here are virtually identical to those reported in a similar analysis of the 2000 election (Jacoby 2004). The features of that earlier contest were quite different from the 2004 presidential election. ${ }^{11}$ So, it seems inappropriate to attribute the lack of a direct structural relationship between ideology and vote choice to any specific circumstances that happened to exist in 2004 .

An alternative, and perhaps more constructive, interpretation is that citizens are actually using their liberal-conservative orientations as ideologies rather than as heuristic devices which merely provide a shortcut to an electoral decision. The basic definition of "ideology" involves a vision of the ideal society, along with the means of achieving it (Downs 1957; Hinich and Munger 1994). Operating in this capacity, a personal ideology should provide useful standards for assessing the leadership potential of public figures, weighing the relative merits of alternative policy positions, and evaluating current social, political, and economic problems. The current analysis shows that this is exactly how liberal-conservative identifications operated within the 2004 electorate: They played a prominent role in structuring individual judgments about the candidates' personal characteristics, a variety of political issues, and the state of the national economy. In other words, liberal-conservative orientations gave people a set of criteria for interpreting the world around them. But, that is precisely what a true ideology is supposed to do!

From this perspective, the lack of a direct ideological effect on voting choice is not particularly troubling. Sniderman, Brody, and Tetlock (1991) argue that ideological identifications can function in both cognitive and affective capacities. In 2004, it simply appears that the cognitive applications of liberal-conservative terms surpassed their utility as affective symbols. Liberal-conservative thinking helped the electorate to organize the salient stimuli of the 2004 campaign environment in a coherent manner. After evaluating the candidates, issues, and prevailing conditions, citizens were able to reach their voting decisions without having to rely upon additional guidance from descriptive labels like "liberal" and "conservative." 
In conclusion, it is important to point out that the findings reported here are perfectly consistent with the theoretical perspective derived from The American Voter. According to Campbell, Converse, Miller, and Stokes (1960), broad predispositions like party identification and ideology exist among the background factors that feed into an individual's electoral decision. But, their impact occurs largely by shaping the more immediate variables that impinge on that decision. This is exactly what we observed in the current analysis: Liberal-conservative identifications affected voting entirely through their influence on the perspectives that people brought to bear on the salient stimuli of the 2004 election. In this manner, the empirical results not only underscore the truly ideological nature of the 2004 presidential election; they also provide important confirmatory evidence to support a general theory that has, for nearly five decades, occupied the central position within scholarly interpretations of mass political behavior. 


\section{NOTES}

1. Of the 822 NES respondents who reported voting for president in 2004, only four, or about $0.5 \%$ voted for Nader.

2. The NES respondents were asked how well each of the following traits described Bush and Kerry: moral; provides strong leadership; really cares about people like me; knowledgeable; intelligent; dishonest; can't make up his own mind. Responses are scored on a 4-point scale, with larger values indicating stronger belief that the specified trait describes the candidate well.

3. The summary issue scale combined responses to questions asking about: government spending versus services; defense spending; government versus private health insurance; government guaranteed jobs and standard of living; aid to Blacks; tradeoffs between the environment and jobs; and women's role in society.

4. The NES respondents were asked "Taking everything into account, do you think the war in Iraq has been worth the cost or not?" and "As a result of the United States military action in Iraq, do you think the threat of terrorism against the United States has increased, decreased, or stayed about the same?"

5. The NES respondents were asked which party had the most members in the U.S. House of Representatives and the U.S. Senate prior to the 2004 elections and they were also asked to identify the offices held by Dennis Hastert, Richard Cheney, Tony Blair, and William Rehnquist.

6. In this context, Kerry, Nader and the Democratic Party are all considered to be liberal stimuli. So, a correct placement in those cases would be scores of one, two, or three on the NES seven-point scale; an incorrect placement would be scores of five, six, or seven. This scoring scheme is reversed for the two conservative stimuli, Bush and the Republican Party.

7. The multidimensional scaling analysis was carried out using the PROC MDS routine in SAS. However, virtually identical results are obtained when other software is used, including the ALSCAL and PROXSCALE routines in SPSS, the multidimensional scaling routine in SYSTAT 11, and the isoMDS function in the MASS package of the $\mathrm{R}$ statistical computing environment.

8. Although not of central importance for the present analysis, the vertical dimension in Figure 1 also seems to have a fairly clear interpretation: Notice that the points representing Ralph Nader and John McCain are both located at relatively high positions within the space (the former much more so than the latter). On the other side, the Hillary Clinton point falls somewhat below most of the other points. Based upon this evidence, the vertical dimension seems to represent either general notoriety or an "insider-outsider" distinction. Once again, external evidence can be used to validate this interpretation: Each figure's status as a party 
"insider" can be measured by taking the mean thermometer ratings provided by identifiers with the same party (i.e., the mean rating by Democrats of Kerry, Nader, Edwards, the Clintons, and the Democratic party itself; the mean rating by Republicans of Bush, Cheney, McCain, Laura Bush, Ashcroft, Powell, and the Republican party). In the MDS configuration, the difference between the vertical coordinates for each figure and the Democratic or Republican party represents how "distant" each figure is from his/her party (of course, the parties are maximally "close" to themselves, since this distance is zero in each case). The correlation between the mean intra-party thermometer ratings and the vertical distances is very large, at 0.839 . Thus, along with ideology, people apparently judged the 2004 candidates according to whether they represent the mainstream of their respective parties or stand as outsiders (for varying reasons).

9. An indirect effect is the change in the log odds of a Bush vote due to the impact of ideology on another intervening variable that, in turn, affects vote choice directly (e.g., Fox 1980). Assume that $\hat{\beta}_{j}$ is the OLS coefficient showing the impact of ideology on variable $X_{j}$ and $\hat{\gamma}_{j}$ is the ML logistic regression coefficient showing the impact of $X_{j}$ on vote choice. The indirect effect of ideology on vote choice, operating through $X_{j}$, would be defined as the product of these two coefficients, $\hat{\beta}_{j} \hat{\gamma}_{j}$. Here, ideology operates through four intervening variables: candidate evaluations, issue attitudes, sociotropic evaluations, and feelings about the Iraq war. Using the coefficients from Tables 1 and 4, the indirect effects of ideology through each of the preceding variables are $0.337,0.206,0.010$, and 0.061 , respectively. The full indirect effect is obtained by summing the separate indirect effects; this produces the value of 0.614 reported in the text. An odds ratio can be obtained for the indirect effect, in the usual manner, by exponentiating the effect on the log odds. In this case, $e^{0.614}=1.848$.

10. The difference between the indirect effect of ideology and the direct effect of party identification on voting choice is not statistically significant. In fact, it is quite difficult to calculate the standard error for the indirect effect of ideology, because the latter is defined as a nonlinear combination of coefficients. However, even ignoring sampling variability in the indirect effect, the probability value for a two-sided test of the null hypothesis that the direct impact of party identification is equal to 0.614 is 0.386 . This null hypothesis would not be rejected at any standard level of statistical testing. Therefore, it is reasonable to conclude that the difference between the sizes of the two effects is due to sampling error.

11. Of course, the Democratic candidates and campaign themes varied across the two years. And, while George W. Bush was a candidate in both cases, his incumbency-based appeals to patriotism and national security concerns in the 2004 campaign were a marked shift from the "compassionate conservatism" that dominated the earlier contest. 


\section{REFERENCES}

Alvarez, R. Michael and Jonathan Nagler. (1995) "Economics, Issues, and the Perot Candidacy: Voter Choice in the 1992 Presidential Election." American Journal of Political Science 39: 714-744.

Alvarez, R. Michael and Jonathan Nagler. (1998) "Economics, Entitlements, and Social Issues: Voter Choice in the 1996 Presidential Election." American Journal of Political Science 42: 1349-1363.

Campbell, Angus; Philip E. Converse; Warren E. Miller; Donald E. Stokes. (1960) The American Voter. Chicago: University of Chicago Press.

Conover, Pamela J. and Stanley Feldman. (1981) "The Origins and Meaning of LiberalConservative Self-Identification." American Journal of Political Science 25: 617-645.

Converse, Philip E. (1964) "The Nature of Belief Systems in Mass Publics." In David E. Apter (Ed.) Ideology and Discontent. New York: Free Press.

Converse, Philip E. (1970) "Attitudes and Nonattitudes: Continuation of a Dialogue." In Edward R. Tufte (Ed.) The Quantitative Analysis of Social Problems. Reading, MA: Addison-Wesley.

Converse, Philip E. (1975) "Public Opinion and Voting Behavior." In Fred I. Greenstein and Nelson W. Polsby (Eds.) The Handbook of Political Science. Reading, MA: AddisonWesley.

Downs, Anthony. (1957) An Economic Theory of Democracy. New York: Harper.

Fox, John. (1980) "Effect Analysis in Structural Equation Models." Sociological Methods and Research 9: 3-28.

Hinich, Melvin J. and Michael C. Munger. (1994) Ideology and the Theory of Political Choice. Ann Arbor, MI: University of Michigan Press.

Jacoby, William G. (1986) "Levels of Conceptualization and Reliance on the LiberalConservative Continuum." Journal of Politics 48: 423-432.

Jacoby, William G. (1988) "The Sources of Liberal-Conservative Thinking: Education and Conceptualization." Political Behavior 10: 316-332.

Jacoby, William G. (1991) "Ideological Identification and Issue Attitudes." American Journal of Political Science 35: 178-205.

Jacoby, William G. (2004) "Ideology in the 2000 Election: A Study in Ambivalence." In Herbert F. Weisberg and Clyde Wilcox (Eds.) Models of Presidential Voting: The 2000 U.S. Election. Stanford, CA: Stanford University Press. 
Kinder, Donald R. (1983) "Diversity and Complexity in Public Opinion." In Ada R. Finifter (Ed.) Political Science: The State of the Discipline. Washington, DC: American Political Science Association.

Knight, Kathleen K. (1985) "Ideology in the 1980 Election: Ideological Sophistication Does Matter." Journal of Politics 47: 828-853.

Krosnick, Jon R. (1991) "The Stability of Political Preferences: Comparisons of Symbolic and Nonsymbolic Attitudes." American Journal of Political Science 35: 547-576.

Levitin, Teresa E. and Warren E. Miller. (1979) "Ideological Interpretations of Presidential Elections." American Political Science Review 73: 751-771.

Miller, Arthur H.; Warren E. Miller; Alden S. Raine; Thad H. Brown. (1976) "A Majority Party in Disarray: Policy Polarization in the 1972 Election." American Political Science Review 70: 753-778.

Miller, Warren E. and Teresa E. Levitin. Leadership and Change: The New Politics and the American Electorate. Cambridge, MA: Winthrop.

Miller, Warren E. and J. Merrill Shanks. (1996) The New American Voter. Cambridge, MA: Harvard University Press.

Rabinowitz, George B. (1976) "A Procedure for Ordering Object Pairs Consistent with the Multidimensional Unfolding Model." Psychometrika 41: 349-373.

Sears, David O. (1993) "Symbolic Politics: A Socio-Psychological Theory." In Shanto Iyengar and William J. McGuire (Eds.) Explorations in Political Psychology. Durham, NC: Duke University Press.

Sears, David O. and Carolyn L. Funk. (1999) "Evidence of the Long-Term Persistence of Adults' Political Predispositions." Journal of Politics 61: 1-28.

Sears, David O.; Richard R. Lau; Tom R. Tyler; H. M. Allen, Jr. (1980) "Self-Interest Versus Symbolic Politics in Policy Attitudes and Presidential Voting." American Political Science Review 74: 670-684.

Sniderman, Paul M.; Richard A. Brody; Philip E. Tetlock. (1991) Reasoning and Choice: Explorations in Political Psychology. Cambridge, UK: Cambridge University Press. 
Table 1: Logistic regression estimates showing the determinants of voting choice in the 2004 presidential election. The dependent variable is coded so that a Bush vote is one and a Kerry vote is zero.

\begin{tabular}{|c|c|c|}
\hline & $\begin{array}{l}\text { Maximum likelihood } \\
\text { coefficient estimate } \\
\text { (standard error } \\
\text { in parentheses) }\end{array}$ & $\begin{array}{l}\text { Odds } \\
\text { ratio }\end{array}$ \\
\hline $\begin{array}{r}\text { Party } \\
\text { Identification }\end{array}$ & $\begin{array}{c}0.510 \\
(0.120)\end{array}$ & 1.666 \\
\hline $\begin{array}{r}\text { Liberal-conservative } \\
\text { self-placement }\end{array}$ & $\begin{array}{c}0.247 \\
(0.188)\end{array}$ & 1.280 \\
\hline $\begin{array}{r}\text { Candidate personality } \\
\text { trait assessments }\end{array}$ & $\begin{array}{c}2.041 \\
(0.327)\end{array}$ & 7.698 \\
\hline $\begin{array}{r}\text { Summary issue } \\
\text { attitudes }\end{array}$ & $\begin{array}{c}0.756 \\
(0.259)\end{array}$ & 2.130 \\
\hline $\begin{array}{r}\text { Sociotropic economic } \\
\text { judgments }\end{array}$ & $\begin{array}{c}0.575 \\
(0.259)\end{array}$ & 1.777 \\
\hline $\begin{array}{l}\text { Feelings about } \\
\text { the Iraq war }\end{array}$ & $\begin{array}{c}0.356 \\
(0.151)\end{array}$ & 1.428 \\
\hline Constant & -4.168 & \\
\hline Pseudo-R ${ }^{2}$ & 0.778 & \\
\hline Log likelihood & -99.828 & \\
\hline Number of observations & 651 & \\
\hline
\end{tabular}

Note: Coefficients for all variables except liberal-conservative self-placement are statistically significant at the 0.05 level (one-sided tests).

Data Source: 2004 CPS National Election Study. 
Table 2: Logistic regression estimates from a conditional effects model of voting choice in the 2004 presidential election. The dependent variable is coded so that a Bush vote is one and a Kerry vote is zero. The impact of the first six independent variables is hypothesized to be conditional upon the level of political knowledge.

\begin{tabular}{|c|c|c|}
\hline & $\begin{array}{l}\text { Maximum likelihood } \\
\text { coefficient estimate } \\
\text { (standard error } \\
\text { in parentheses) } \\
\end{array}$ & $\begin{array}{c}\text { Multiplicative term } \\
\text { between variable and } \\
\text { knowledge scale (standard } \\
\text { error in parentheses }\end{array}$ \\
\hline $\begin{array}{r}\text { Party } \\
\text { Identification }\end{array}$ & $\begin{array}{c}0.724 \\
(0.260)\end{array}$ & $\begin{array}{c}-0.069 \\
(0.077)\end{array}$ \\
\hline $\begin{array}{r}\text { Liberal-conservative } \\
\text { self-placement }\end{array}$ & $\begin{array}{c}0.264 \\
(0.426)\end{array}$ & $\begin{array}{c}0.002 \\
(0.126)\end{array}$ \\
\hline $\begin{array}{r}\text { Candidate personality } \\
\text { trait assessments }\end{array}$ & $\begin{array}{l}1.908 \\
(0.678)\end{array}$ & $\begin{array}{c}0.067 \\
(0.211)\end{array}$ \\
\hline $\begin{array}{r}\text { Summary issue } \\
\text { attitudes }\end{array}$ & $\begin{array}{l}0.815 \\
(0.660)\end{array}$ & $\begin{array}{l}0.006 \\
(0.176)\end{array}$ \\
\hline $\begin{array}{r}\text { Sociotropic economic } \\
\text { judgments }\end{array}$ & $\begin{array}{l}1.035 \\
(0.572)\end{array}$ & $\begin{array}{c}-0.138 \\
(0.164)\end{array}$ \\
\hline $\begin{array}{l}\text { Feelings about } \\
\text { the Iraq war }\end{array}$ & $\begin{array}{c}-0.289 \\
(0.360)\end{array}$ & $\begin{array}{c}0.202 \\
(0.105)\end{array}$ \\
\hline $\begin{array}{r}\text { Political } \\
\text { knowledge }\end{array}$ & $\begin{array}{c}-0.839 \\
(0.913)\end{array}$ & \\
\hline Constant & -1.622 & \\
\hline Pseudo-R ${ }^{2}$ & 0.785 & \\
\hline Log likelihood & -96.850 & \\
\hline Number of observations & 651 & \\
\hline
\end{tabular}

Note: For the first six variables, the coefficient in the left-hand column shows the effect of that independent variable when the political knowledge variable is equal to zero. For each of these variables, the coefficient in the right-hand column gives the change in that variable's impact on the vote that occurs with a single unit increase in the political knowledge variable. None of the coefficients for the multiplicative terms are statistically different from zero (two- sided test).

Data Source: 2004 CPS National Election Study. 
Table 3: Citizen placements of 2004 candidates and parties along the liberal-conservative scale.

\begin{tabular}{|c|c|c|c|}
\hline & $\begin{array}{l}\text { Percentage placing } \\
\text { along the liberal-- } \\
\text { conservative scale }\end{array}$ & $\begin{array}{l}\text { Percentage placing at } \\
\text { "correct" location } \\
\text { along the liberal-- } \\
\text { conservative scale }\end{array}$ & $\begin{array}{l}\text { Percentage placing at } \\
\text { "incorrect" location } \\
\text { along the liberal- } \\
\text { conservative scale }\end{array}$ \\
\hline \multicolumn{4}{|l|}{ Candidates: } \\
\hline Bush & 89.44 & 64.36 & 15.92 \\
\hline Kerry & 89.77 & 59.08 & 12.95 \\
\hline Nader & 64.69 & 40.02 & 9.57 \\
\hline \multicolumn{4}{|l|}{ Parties: } \\
\hline Democratic Party & 90.51 & 60.56 & 14.19 \\
\hline Republican Party & 90.02 & 66.01 & 13.94 \\
\hline
\end{tabular}

Note: The number of observations used to calculate the percentages ranges from 784 to 1097.

Data Source: 2004 CPS National Election Study. 
Table 4: The impact of party identification and liberal-conservative ideology on Bush-Kerry personality assessments, issue attitudes, sociotropic economic judgments, and feelings about the Iraq war.

\begin{tabular}{rcccc}
\hline \hline & Party & $\begin{array}{c}\text { Liberal- } \\
\text { conservative } \\
\text { self-placement }\end{array}$ & Intercept & $\mathrm{R}^{2}$ \\
identification & 0.370 & 0.165 & -1.816 & 0.584 \\
Bush-Kerry & $(0.016)$ & $(0.023)$ & & \\
Issue & 0.172 & 0.273 & 2.033 & 0.428 \\
attitudes & $(0.015)$ & $(0.022)$ & & \\
Sersonality assessments & 0.206 & 0.017 & 1.945 & 0.265 \\
judgments & $(0.014)$ & $(0.021)$ & & \\
Feelings about & 0.388 & 0.172 & 0.765 & 0.414 \\
the Iraq war & $(0.023)$ & $(0.033)$ & & \\
\hline
\end{tabular}

Note: Entries are OLS regression coefficients. Coefficients in the two left columns are all statistically greater than zero (0.05 level) except for the impact of liberal-conservative ideology on sociotropic economic judgments. The number of observations ranges from 907 to 914 .

Data Source: 2004 CPS National Election Study. 
Figure 1: Perceptual space for 2004 political figures and parties.

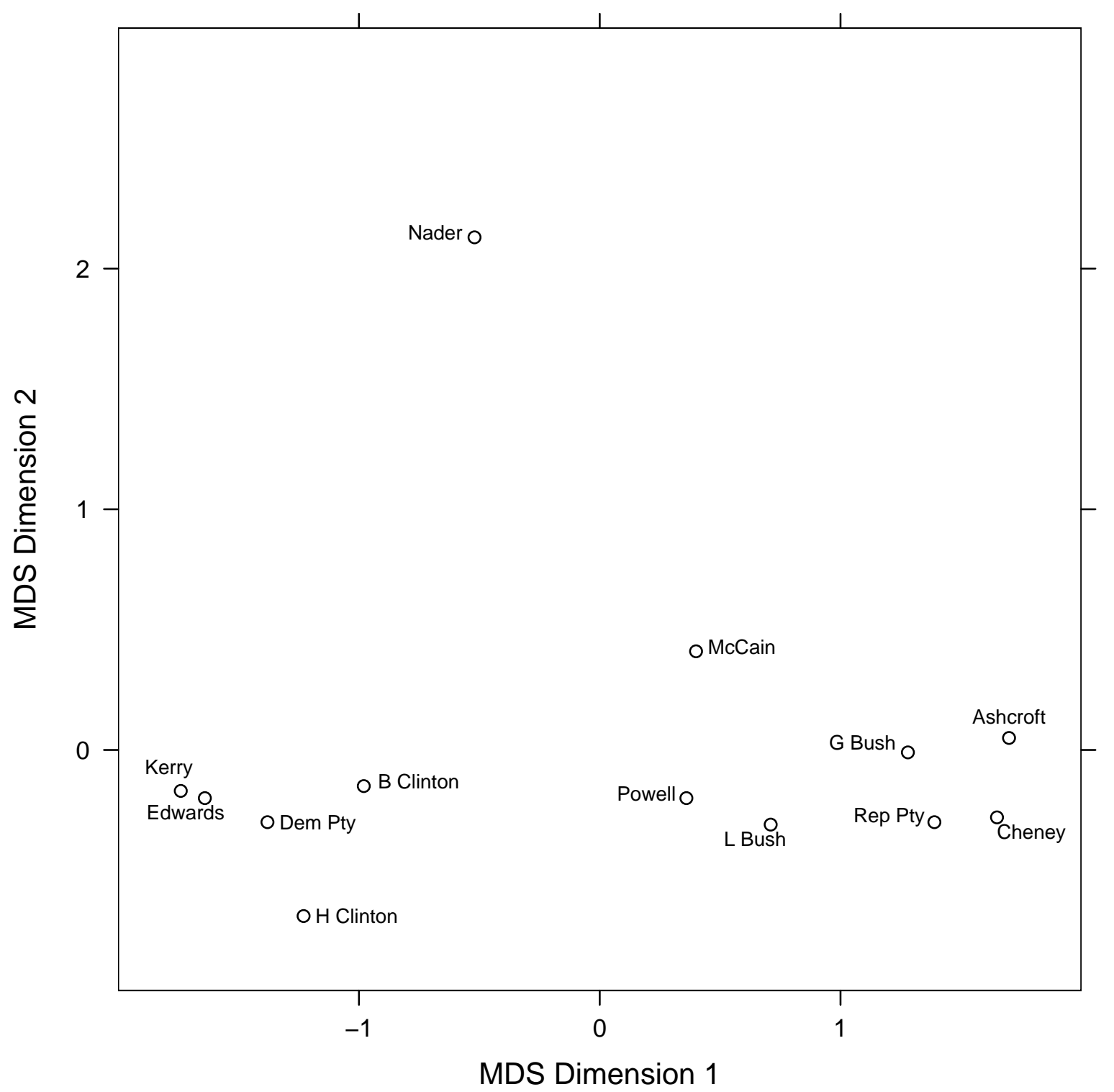

Note: This configuration is obtained from a nonmetric multidimensional scaling analysis of LOS dissimilarities. The latter are calculated from feeling thermometer ratings of the stimuli given by the 2004 NES respondents. The scaling solution has a Stress 1 value of 0.04 and the correlation between the (optimally transformed) dissimilarities and the scaled distances is 1.00 . 